\title{
Strategies on the Construction of Language and Cultural Environment for Bilingual Teaching in Higher Vocational Colleges
}

\author{
Yan Zeng \\ Yunnan Open University, Kunming, Yunnan Province, China
}

Keywords: higher vocational colleges; bilingual teaching; language and cultural environment; exploration

\begin{abstract}
On the basis of the importance of language and cultural environment on bilingual teaching, this paper analyzes the present situation and existing problems of students' language and cultural environment in the Chinese-foreign cooperative project of bilingual teaching. The paper analyzes methods and strategies which can create good language and cultural environment as well as the international learning atmosphere. These strategies can promote the development of bilingual teaching, and cultivate students' abilities of using language as a medium to acquire knowledge and information.
\end{abstract}

\section{Introduction}

The inseparable relationship between human and space determines the importance of students' adaptabilities to the environment; the cultural environment of students plays a very important role in their learning effects. The purpose of studying the relationship between learners and the environment is to find out useful approaches which can promote the development of bilingual teaching and realize effective student management. The effective utilization of environment can cultivate and improve students' abilities of using language as a medium to acquire knowledge and information. Language environment is very important to language mastery and usage; it provides students with practice opportunities. Thus, in the process of bilingual teaching, a good language and cultural environment must be built for students.

\section{Present Situation of Language and Cultural Environment}

According to investigations on the language and cultural environment in higher vocational colleges of Yunnan, and the analysis of information about the language and cultural environment in higher vocational colleges of other provinces, the present situations of language and cultural environment are analyzed as follows.

\subsection{Present situation of cultural environment in class}

At present, the overall level of vocational college students is relatively low; individual differences among these students are great. Students who are good at English do not have high practical abilities. The survey shows that students' attitudes towards English learning are diversified. Some students learn English in order to enter a higher school; some students learn English in order to complete their course tasks and get the diploma; some students want to lay a good foundation for their future employment. These learning purposes are utilitarian, and cannot guarantee students' persistence in English learning. In addition, these students must use English, rather than their mother tongue, to learn subject knowledge. Difficulties in learning lead to students' anxiety. Meanwhile, due to the expending enrollment of colleges, the number of students in each class increases. Teachers have to pay more efforts in classroom control. Interaction opportunities reduce; the effect of bilingual teaching is weakened. At present, bilingual teachers have limited teaching abilities and proficiencies in English; they cannot effectively control students in the classroom. In the early stage of bilingual teaching, teachers use Chinese for most of the time; English only occupies $20 \%$ to $30 \%$ in the 
classroom teaching. The language abilities of teachers and students cannot reach the requirement of creating a good classroom language environment.

\subsection{Present situation of cultural environment in campus}

The cultural system of most higher vocational colleges in Yunnan is a vertical system. Students obey to teachers; teachers obey to departments; departments obey to the school. Feelings and suggestions of students and teachers are rarely respected or adopted. Schools are lack of bottom-up humanistic atmosphere centered on students and teachers, and are lack of respects for individuals. Now only a small number of students are involved in Chinese-foreign cooperation projects; higher vocational colleges do not publicize these projects and bilingual teaching. Most of the higher vocational colleges are unable to create the language environment of bilingual teaching.

\subsection{Present situation of language and cultural environment in families}

Family environment has lifelong influence on students' learning. In Canada, America, Singapore, Australia and other countries, one person in students' parents or older generations can use students' second language. They can communicate in the language after school. In China, such family language environment is uncommon, which limits the expansion and consolidation of bilingual teaching effects.

\section{Creating International Language and Cultural Environment for Higher Vocational College Students}

The good language and cultural environment and the international learning atmosphere can help students to improve their English competence, and enhance their abilities of using English as a medium to learn professional knowledge. They also help students to learn foreign culture, and improve their abilities and consciousness on cross cultural communication when they study professional courses.

\subsection{Creating classroom language and cultural environment with humanistic connotations}

The requirement of bilingual teaching on classroom environment is to build a student-based classroom cultural environment. Teachers' attentions to students will help students to become better, and promote the transformation of teachers' roles from the master of class to instructor and collaborator of students, which is beneficial to the establishment of a new teacher-student relationship.

Enhance the levels of interaction. In normal bilingual teaching, the main form of interaction is question and answer; but a single interaction method is not enough. Students should become the subjects of learning. Teachers can provide students with relevant topics, and ask them to collect information, discuss the topic in groups, write speech materials, and submit or produce courseware before class. In class, students need to explain their ideas and views. The bilingual communication between students and students can not only improve students' English abilities, but also broaden their professional visions and cultivate their professional thinking. Most of the teachers in Australia explain little in class; they arrange learning tasks, make requests, organize teaching process and make brief comments. In particular, the practice courses are designed by students themselves. The teacher is only responsible for the evaluation of students' works. Students need to modify their works on the basis of teachers' evaluation. The whole learning process is completed basically by students.

Creating relaxed classroom atmosphere. Multimedia equipment should be used to create a relaxed learning atmosphere. Some abstract contents and teaching difficulties can be displayed through multimedia courseware; the contents of bilingual teaching should be closely combined with the application of modern educational technology; relevant video data should be carefully collected and designed. By watching video, students are access to knowledge more directly. By thinking and discussing video contents, students can participate in bilingual teaching from the perspectives of vision, hearing, thinking and expression, which will improve their learning interests. 


\subsection{Creating international language and cultural environment in campus}

The creation of the humanistic atmosphere in schools will exert a subtle influence on students' growth. Under the background of Chinese-foreign cooperation, the good language and cultural environment and the international learning atmosphere are helpful to the development of bilingual teaching, and can cultivate students' abilities of using language as a medium to acquire knowledge and information.

The publicity of Chinese-foreign cooperation projects and bilingual teaching. Through the publicity of Chinese-foreign cooperation projects and bilingual teaching, teachers and students can understand and support the bilingual teaching project. In order to build good language and cultural atmosphere, a series of activities should be carried out in campus. Schools can design bilingual websites for Sino-foreign cooperation projects, and set up bilingual teaching topics to create a good language atmosphere. Meanwhile, schools can provide conditions to help students and teachers to carry out activities of English Salon. Compared with English corner, English Salon has more diverse scopes, themes and forms. English Salon should be organized by students under the guidance of teachers. Schools should provide sites and facilities. Through these ways, schools can establish international language and cultural atmosphere which will stimulate students' enthusiasm and interest in learning English and participating in bilingual teaching.

Two-way exchange students project. Schools should strengthen exchanges and communication with foreign universities, and set up a two-way exchange students project. The two-way exchange student project provides students with opportunities to study abroad. Meanwhile, through the introduction of short term foreign students, the atmosphere of bilingual classroom can be activated; the communication between vocational college students can be promoted. International language and culture atmosphere can be formed in Chinese-foreign cooperative classes.

Short term study abroad project. This project is different from two-way exchange students project. A small number of students can choose to study abroad for one semester or one year, and get corresponding credits in cooperative schools. After returning to school, they need to complete their studies in China. Cooperative foreign schools do not need to send students to study in China. This project provides students with the opportunity to study abroad, to experience foreign culture and broaden international vision; it can improve students' foreign language using abilities and intercultural communication abilities.

Two-way teaching and social practice during vacations. This is a two-way project carried out between Chinese and foreign schools. During winter and summer vacations, students from cooperative classes can be organized by full-time teachers to visit universities abroad for half month to one month and carry out teaching activities, field investigation and social practice. During this period, students can learn the advanced teaching modes, the educational environment, the campus culture and the urban development of foreign countries. This project can increase communication between Chinese and foreign institutions, deepen mutual understanding and promote the close cooperation between two parities. It can also create international cultural atmosphere in campus.

Hiring foreign teachers. In the Chinese-foreign cooperation project, foreign schools should send full-time teachers to instruct Chinese students from cooperative classes. Students can learn from foreign teachers directly. This is an advantage of the cooperative education project, and can promote the process of bilingual teaching. Foreign teachers can impart professional knowledge from different perspectives, bring new teaching ideas and build international language and cultural atmosphere, thus stimulate the enthusiasm of students in learning bilingual courses.

Foreign experts' lectures. In the process of cooperation, foreign experts from cooperative schools or enterprises can be invited to visit Chinese schools irregularly. Their lectures and academic reports are conducive to the creation of international cultural environment. Students can understand professional theories and practices from the international perspective. These lectures will improve students' abilities to analyze and solve problems, and lay the foundation for establishing international thinking mode.

Bilingual class management. The construction of bilingual teaching environment is inseparable 
from the management of bilingual classes. Students' extracurricular activities, student cadre election and class management should be carried out on the basis of bilingual teaching. Counselors should join in the Sino-foreign cooperative project, learn English together with full-time teachers, and participate in various teaching staff construction projects. The management of bilingual classes provides students with a large number of opportunities to use English outside the classroom, and helps to create good language and culture environment.

\subsection{Creating interaction between family and school in the cultural environment}

Family is the birthplace of education; its impact on students is lifelong. Family environment is very important for language acquisition. However, when students enter professional schools, they are separated from the family environment. Therefore, the school should frequently communicate with parents and tell them about students' performance in school as soon as possible, and get feedbacks from parents. This process can deepen the relationship between schools and parents, and enhance parents' understanding on the importance of bilingual education. Through informal discussion between parents and students, and regular communication between parents and schools, a two-way communication mechanism can be build to create excellent cultural environment in families.

\subsection{Creating cultural environment which links to the society and international enterprises}

The development of higher vocational schools cannot be separated from the supports of enterprises and the society. The ultimate goal of students' learning is to use their knowledge in enterprises and the society. If students do not know the path of their future career, their learning goals will be unclear. Therefore, it is particularly important to establish the relationship between school learning and career path. Schools should create opportunities for students to contact with the society and enterprises. For instance, students can visit international enterprises in training courses; principals of cooperative enterprises can be invited to give lectures, introducing the situations of enterprises and the requirements of talents. The current situation and prospect of the industry can also be introduced. Human resources personnel can also be invited to hold simulated recruitment meetings, in order to provide students with the opportunity of practicing job interviews. Through the interaction with international enterprises, students can fully understand the requirements of enterprises and the importance of English abilities in career development. Through these activities, students can find their career development paths.

\section{References}

[1] A.Y. Huang, Research on Theory and Practice of Bilingual Teaching, Shanghai People's Publishing House, Shanghai, 2011.

[2] J. Cui, The relevance between social environment and bilingual teaching, J. Tribune of Social Sciences in Xinjiang. 6 (2008).

[3] J.R. He, G.S. Li, A New Approach to Bilingual Teaching at Home and Abroad, Science Press, Beijing, 2010.

[4] X.J. Du, Reflection on class culture of bilingual teaching, J. Educational Research. 1 (2007).

[5] A.Y. Huang, Quality education in South Austria, J. Education Approach. 1 (2003).

[6] C.Y. He, On multiculturalism of Canada and bilingual teaching in higher education, J. Yunnan Higher Education Research. 1 (1997).

[7] J.J. Sun, Review of “immersion” bilingual education in Quebec, Canada, J. Journal of Hubei Adult Education Institute. 6 (2009).

[8] Y.Z. Zhao, Chinese Foreign Cooperation in Running Schools: Governance and Development, Dongbei University of Finance and Economics Press, Dalian, 2010.

[9] J.F. Yu, Bilingual teaching in tourism courses, J. Tourism Tribune. S1 (2004). 
[10] N. Wang, The construction and practice of bilingual teaching mode in main courses of tourism major course system, Tourism Tribune. S1 (2005).

[11] Y. Wang, Theory and Practice of Bilingual Education: Comparative Study of Bilingual Education at Home and Abroad, Shanghai Educational Publishing House, Shanghai, 2008.

[12] Q. Yang, Comparative analysis on English education and bilingual teaching in colleges and universities, J. Higher Education Research. 1 (2009).

[13] L.L. Shao, Strategies for the effective construction of English culture in colleges and universities in light of Constructivist Theory, J. Journal of Higher Education. 21 (2015).

[14] S.L. Guo, C.A. Jia, creating an atmosphere of English culture in campus and improving the comprehensive English abilities of college students, J. Time Education. 19 (2015).

[15] Y.F. Yang, H. Luo, Analysis on the promoting effects of creating English cultural environment in campus on the practical teaching of college English, J. English on Campus. 04 (2015).

[16] A.Z. Lan, University archives and strategies for campus culture construction, J. Time Education. 01 (2015). 